\title{
Isoniazid - induced chronic cutaneous Lupus erythematosus
}

\author{
Chiriac $A^{1}$, Brzezinski $P^{2}$, Chiriac AE $E^{3}$, Foia $L^{4}$, Mihaila $D^{5}$, Solovan $C^{6}$ \\ ${ }^{1}$ Head of Department of Dermatology, Nicolina Medical Center, Iasi, Romania; ${ }^{2}$ Head of Department \\ of Dermatology, $6^{\text {th }}$ Military Support Unit, Ustka, Poland; ${ }^{3}$ Student, Department of Dermatology \\ University of Medicine and Pharmacy "Gr. T. Popa” Iasi, Romania; ${ }^{4}$ Head of Department of \\ Dermatology, University of Medicine and Pharmacy "Gr. T. Popa" Iasi, Romania; ${ }^{5}$ Assistant, \\ Department of Dermatology, University of Medicine and Pharmacy "Gr. T. Popa” Iasi, Romania; \\ ${ }^{6}$ Head of Department of Dermatology, University of Medicine V Babes, Timisoara, Romania
}

\begin{abstract}
A 23-year-old man developed drug-induced chronic cutaneous lupus erythematosus 8 months after isoniazid (INH) therapy for pulmonary tuberculosis. Diagnosis was based on clinical aspects (discoid lesions on the face, erythema, photosensitivity, hyperpigmentation), histopathological examination, along with direct immunofluorescence examination (DIF), the absence of systemic involvement and the routine laboratory parameters, which registered all within normal range. Hydroxychloroquine therapy associated to photo protection and emollients determined the clear up of the facial eruption within six months. Transient residual hyperpigmentation could be noticed 2 months after discontinuation of the treatment. This case illustrates a rare form of drug-induced chronic cutaneous lupus erythematosus developed 2 months after withdrawal of antituberculosis therapy, with excellent results with hydroxychloroquine.
\end{abstract}

Keywords: Drug-induced chronic cutaneous lupus erythematosus, Isoniazid, Tuberculosis

Address for correspondence

Piotr Brzezinski, MD PhD

Department of Dermatology, 6th Military Support Unit,

os. Ledowo 1N, 76-270 Ustka, Poland

Mob: +48692121516

Fax:+48598151829

Email: brzezoo77@yahoo.com

\section{Introduction}

Despite that the etiologic factor has long been discovered, tuberculosis represents still a nationwide public health problem in Romania. Among the antitubercular drugs, INH is by far one of the most frequently used, with good therapeutic results. INH has been reported as related mainly to drug-induced subacute cutaneous lupus erythematosus. However, in our case it was cutaneous discoid lupus erythematosus, occurred two months after cessation of the medication for previous pulmonary tuberculosis.

\section{Case report}

A 23-year-old male student presented in September 2012 for evaluation of slightly pruritic erythematous, hyperpigmented plaques on the malar areas, with atrophy in the center of the lesions. There were no scales, and the lesions were distributed symmetrically on the face (Figure 1). 


\section{Case Report}

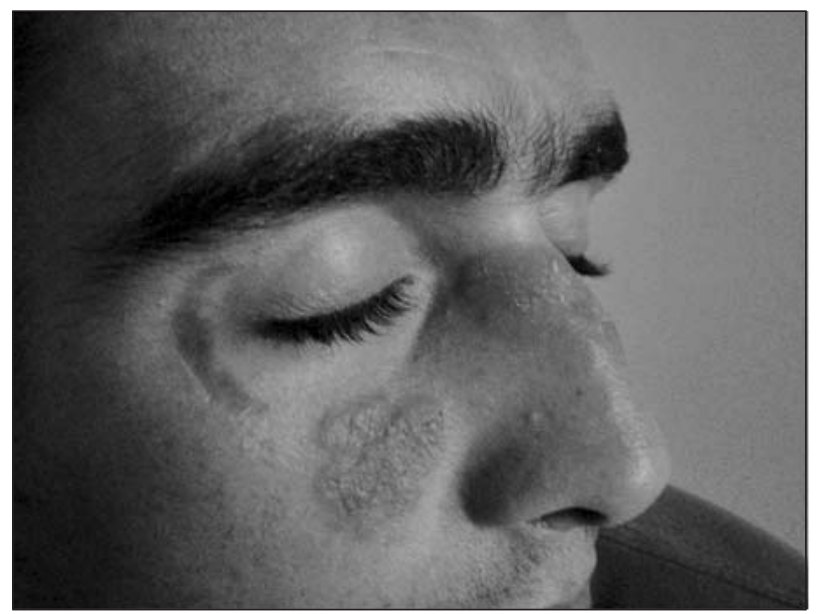

Figure 1: Clinical aspect

The patient noticed the presence of the cutaneous lesions 3 weeks prior to our medical consult and 2 months after completing a 6 months therapy with isoniazid, streptomycin, and ethambutol for pulmonary tuberculosis. He had been hospitalized for 3 months for pulmonary tuberculosis and was treated with isoniazid, streptomycin, and ethambutol for 6 months with full recovery. The last hospitalization in the Pneumology Department of the University Hospital was in January 2012. The investigations made on that occasion revealed negative PPD test (purified protein derivative), no specific lesions on thoracic radiography and computed tomography, while the culture for Mycobacterium tuberculosis was also negative. The patient declined any systemic symptoms (fatigue, fever, arthralgia, gastrointestinal impairments), drug intake, family or personal history of illness beside the tuberculosis one year before. The dermatological examination allowed the clinical diagnosis of chronic cutaneous lupus erythematosus (CCLE).

A $5 \mathrm{~mm}$ punch biopsy from right malar area was performed. The histologic specimen was stained with hematoxylin eosin and revealed the following histopathologic changes in favour of CCLE: focal band-like inflammatory lymphocytes infiltrate and vacuolar alteration at the dermo-epidermal junction, rare necrotic keratinocytes, ortho- and parakeratosis (Figure 2).

Gram and acid-fast-bacilli staining were negative.

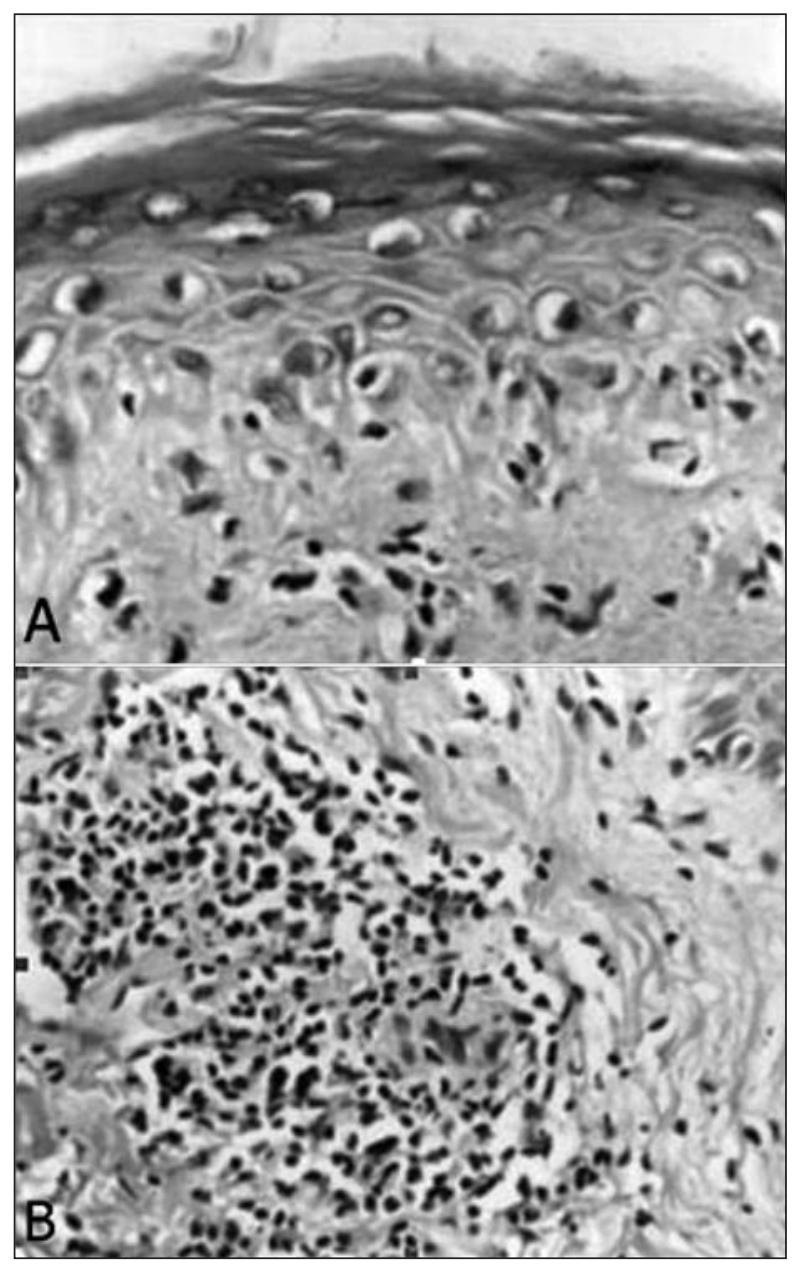

Figure 2: Histological aspects of lesions in photonic microscopy.

The panel of laboratory parameters evaluated comprised: complete blood count, erythrocyte sedimentation rate, extensive metabolic panel, C-reactive protein, $\mathrm{C} 3$, and $\mathrm{C} 4$, which were all within normal range. Anti-nuclear antibody titer, antihistone antibodies, anti-Ro/SS-A, anti-ds DNA, and anti La/SSB antibodies were normal. Drug-induced chronic cutaneous lupus erythematosus was the final diagnosis, based mainly on clinical aspects of cutaneous lesions and histopathological features, the drug incriminated being isoniazid.

The treatment with hydroxychloroquine $200 \mathrm{mg} /$ day was started and after 6 months of therapy full recovery of cutaneous lesions was achieved. Only slight hyperpigmentation was noticed as a residual mark. 


\section{Case Report}

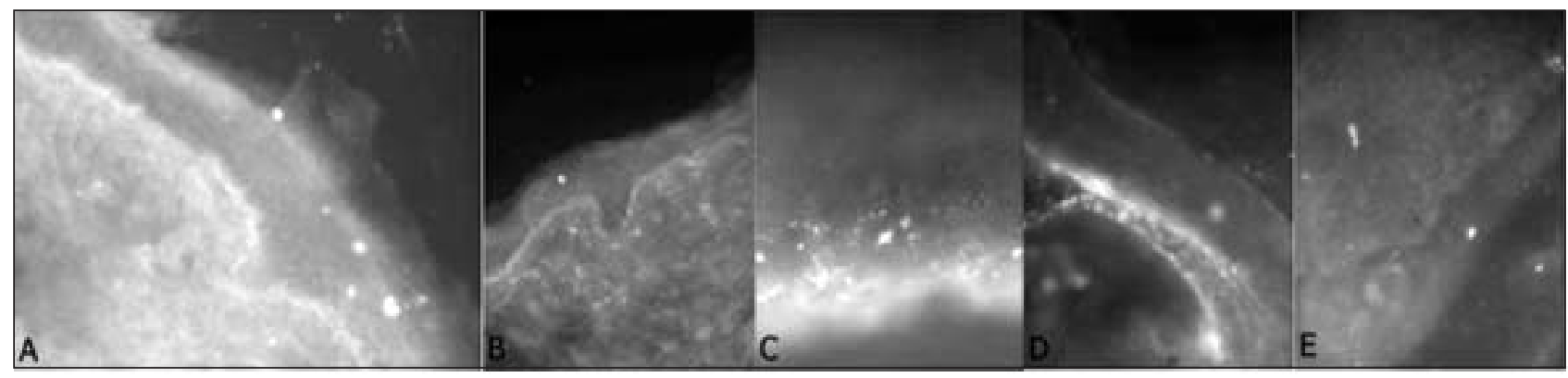

Figure 3: Direct immunofluorescence examination:A.vacuolar alteration at the dermoepidermal junction (HEx 100); B. inflammatory infiltrate of lymphocytes (HEx 100) Direct immunofluorescence examination was consistent with Lupus erythematosus ("lupus band"): C fraction (C1 and C3) and IgG band-like deposits along the basal membrane (Figure 3). $\mathrm{C}$ fraction (C1 and $\mathrm{C} 3$ ) and IgG bandlike deposits along the basal membrane. A. C1x100; B.C3x100; C. IgAx200; D. IgGx200; E. IgMx100

\section{Discussion}

Isoniazid is one of the first-line anti-tuberculosis therapies. The main mechanism of isoniazid action relies on inhibiting mycolic acid synthesis, otherwise essential for the integrity of the mycobacterial cell wall. ${ }^{1}$

Drug induced lupus erythematosus is defined by clinical manifestations, histological modifications and immunopathological parameters similar to those of idiopathic lupus, but temporarily related to continuous drug exposure (from 1 month to years) and resolved after discontinuation of the offending drug. ${ }^{2}$

Drug induced lupus erythematosus is classified into (Table 1$).^{2-5}$

- drug induced systemic lupus erythematosus (DSLE)

- drug induced subacute cutaneous lupus erythematosus (DSCLE)

- drug induced chronic cutaneous lupus erythematosus (DCCLE)

- Anti-TNF $\alpha$ (anti-tumor necrosis factor- $\alpha$ ) therapies are the latest class of medications found to be associated, rarely, with a "lupuslike" syndrome, lately named: anti-tumor necrosis factor-alpha induced lupus (ATIL); Diagnosis is made when there is a temporal relationship between symptoms and anti TNF- $\alpha$ therapy, and at least one serologic and one non-serologic American College of Rheumatology criteria; ${ }^{6}$

- $\quad{ }^{\dagger}$ NSAIDs - Non steroid anti-inflammatory drugs

There are numerous drugs implied in the pathogenesis of lupus erythematosus. The following drugs are associated frequently with erythematous lupus: hydralazine, procainamide, isoniazid, methyldopa, chlorpromazine, quinidine, minocycline. In these cases the disease is very frequent in women, the antihistone antibodies are usually absent, but pANCA are frequently present. Also, it present a hepatic involvement, sometimes followed by chronic hepatitis. ${ }^{5,7-9}$

A possible role in pathogenesis of erythematous lupus was reported for anticonvulsants, antithyroids, penicillamine, $\beta$-blockers, interferon $\alpha$, statins (systemic lupus erythematosus), 5fluorouracil (discoid lupus on photoexposed areas), thiazide diuretics, terbinafine (the latest induce subacute cutaneous lupus erythematosus), verapamil. ${ }^{2,5,8}$

A drug rarely reported to have a role in inducing lupus (sporadic case reports) is lamotrigine ${ }^{10}$ and anti-tumor necrosis factor-alpha (anti-TNF). An uncertain role was attributed to: interleukin 2 (IL2), clobazam, clozapine, tocainide, lisinopril, zafirlukast, capecitabine, bevacizumab, but the clarification of situation needs further researches. ${ }^{11,12}$

\section{Conclusion}

Isoniazid is one of the first-line anti-tuberculosis therapies used in Romania. Our country reports 
Case Report

\begin{tabular}{|l|l|l|l|}
\hline & DSLE & DSCLE & DCCLE \\
\hline Frequency & Most frequent & Rare & Very rare \\
\hline $\begin{array}{l}\text { Antinuclear } \\
\text { antibodies }\end{array}$ & Positive in most cases & Usually positive & $\begin{array}{l}\text { Positive in 2/3 of } \\
\text { cases }\end{array}$ \\
\hline $\begin{array}{l}\text { Antihistone } \\
\text { antibodies } \\
\text { (serum } \\
\text { marker! })\end{array}$ & $\begin{array}{l}\text { Positive in most cases } \\
\text { (75\% present over 20\% in } \\
\text { Idiopathic Systemic Lupus } \\
\text { Erythematosus })\end{array}$ & Very rare positive & Negative \\
\hline $\begin{array}{l}\text { Drugs } \\
\text { implicated }\end{array}$ & $\begin{array}{l}\text { Hydralazine } \\
\text { Procainamide } \\
\text { Isoniazid } \\
\text { Minocycline } \\
\text { Quinidine }\end{array}$ & $\begin{array}{l}\text { Calcium channel blockers } \\
\text { Angiotensin-converting } \\
\text { enzyme inhibitors } \\
\text { Thiazide diuretics } \\
\text { Terbinafine } \\
\text { TNF-alfa antagonists* } \\
\text { Proton pump inhibitors } \\
\text { Chemotherapeutic agents }\end{array}$ & $\begin{array}{l}\text { Fluorouracil agents } \\
\text { TNF-alfa } \\
\text { antagonists* } \\
\text { NSAIDs } \\
\dagger\end{array}$ \\
\hline $\begin{array}{l}\text { Cutaneous } \\
\text { lesions }\end{array}$ & $\begin{array}{l}\text { Purpura, Vasculitis, Raynaud's } \\
\text { Syndrome, Erythema } \\
\text { nodosum, } \\
\text { Photosensitivity, } \\
\text { Alopecia, Malar rash }\end{array}$ & $\begin{array}{l}\text { The same clinical aspect as in } \\
\text { idiopathic form, generalized } \\
\text { lesions and involvement of the } \\
\text { lower legs }\end{array}$ & $\begin{array}{l}\text { Classic discoid } \\
\text { lesions } \\
\text { Lupus tumidus }\end{array}$ \\
\hline
\end{tabular}

annually a high incidence of pulmonary tuberculosis, especially in young patients. Isoniazid has been involved and reported in drug induced lupus erythematosus mainly in women. Our case describes a young male diagnosed with discoid chronic cutaneous lupus erythematosus, occurred 2 months after discontinuation of antituberculosis therapy, with good evolution under hydroxychloroquine and minor residual hyperpigmentation.

What's known? Isoniazid is one of the first-line anti-tuberculosis therapies used in our country. Romania reports annually a high incidence of pulmonary tuberculosis especially in young patients, as in our case. Isoniazid acts by inhibiting mycolic acid synthesis, which is essential for the integrity of the mycobacterial cell wall. Isoniazid has been implicated and reported to trigger drug-induced lupus erythematosus.

What's new? The case outlines some particularities:

1. Isoniazid is related mostly to drug induced subacute cutaneous lupus erythematosus; in our case, however, it was a discoid chronic cutaneous lupus erythematosus;

2. Drug induced lupus erythematosus is temporarily related to continuous drug exposure (one month to years), but in our case cutaneous manifestations occurred 2 months after cessation of the medication for previous pulmonary tuberculosis;

3. Drug induced chronic cutaneous lupus erythematosus is very rarely reported in the literature;

4. Isoniazid is accepted to have a certain role in inducing lupus erythematosus mainly in women, while our patient is a young male;

5. Antinuclear antibodies and antihistone antibodies were negative;

6. Antituberculosis therapy in our patient consisted of isoniazid, streptomycin and ethambutol and, based on the previous reports upon drugs involved in inducing lupus erythematosus, we assumed that isoniazid was the culprit;

7. We could not identify any explanation for the residual hyperpigmentation. 


\section{References}

1. Küçükünal A, Ekmekçi TR, Sakiz D. "Turkey Ear" as a cutaneous manifestation of tuberculosis. Indian J Dermatol 2012; 57: 504.

2. Abreu Velez AM, Brown VM, Howard MS. A transient drug induced lupus erythematosus - like allergic drug reaction with multiple antibodies. Our Dermatol Online 2013; 4: 511-3.

3. Marzano AV, Vezzoli P, Crosti C. Drug-induced lupus: an update on its dermatologic aspect. 2009; 18: 935-40.

4. Abreu Velez AM, Klein AD, Howard MS. Skin appendageal immune reactivity in a case of cutaneous lupus. Our Dermatol Online 2011; 2: 175-80.

5. Di Martino Ortiz B. Interface drug induced dermatitis from mild to severe forms. a dermatopathological view. Our Dermatol Online 2012; 3: 10-16.

6. H, Y, H, Alyasi O. Anti-Tumor Necrosis Factor-á Induced Systemic Lupus Erythematosus. Open Rheumatol J 2012; 6: 315-19.

7. Abreu Velez AV, Klein AD, Howard MS. An allergic bullous drug reaction triggered by levofloxacin and trimethoprim/sulfamethoxazole mimicking an autoimmune blistering disease. Our Dermatol Online 2012; 3: 342-4.

8. Kurtis B, Larson MJ, Hoang MP, Cohen JB. Case report: verapamil-induced subacute cutaneous lupus erythematosus. J Drugs Dermatol 2005; 4: 506-8.

9. Abreu Velez AM, Avila IC, Howard MS. Immune response in a cutaneous allergic drug reaction secondary to imidapril, benazapril and metformin. Our Dermatol Online 2013; 4: 192-5.

10. Khattri S, Kushawaha A, Dahal K, Lee M, Mobarakai N. Isoniazid (INH)-induced eosinophilic exudative pleural effusion and lupus erythematosus: a clinical reminder of drug side effects. Bull NYU Hosp Jt Dis 2011; 69: 181-4.

11. Cleaver N, Ramirez J, Gildenberg S. Cutaneous lupus erythematosus in a patient undergoing intravitreal bevacizumab injections: case report and review of the literature. J Drugs Dermatol 2013; 12: 1052-5.

12. Wiesenthal A, Matherne R, Gibson B. Capecitabine-induced systemic lupus erythematosus and palmoplantar erythrodysesthesia. J Drugs Dermatol 2012; 11: 769-71. 